\title{
ULTRA LOW SULFUR DIESEL FUEL PERFORMANCE
}

\author{
Helineia Oliveira Gomes ${ }^{1}$, Tadeu Cavalcante Cordeiro de Melo ${ }^{1}$, \\ Carlos Vinicius Costa Massa ${ }^{1}$, Airton Giongo ${ }^{1}$
}

Petróleo Brasileiro S.A.

E-mails: helineia@petrobras.com.br, tcm@petrobras.com.br, cmassa@petrobras.com.br e airton.giongo@petrobras.com.br

\begin{abstract}
The increasing concern regarding air quality improvement has guided the environmental legislation to establish severe restrictions goals for vehicular pollutants reduction. The ongoing search for cleaner-burning fuels does not necessarily result in appropriate fuel performance. Such restrictions directly impact the refining scheme of diesel fuel production and reflect on changes in its chemical composition. The severe refinery hydro-processing being introduced to remove sulfur, also reduces surface active compounds and antioxidants, potentially changing the final properties of the low sulfur diesel oil produced. The S10 diesel fuel $(10 \mathrm{mg} / \mathrm{kg}$ of sulfur) was released in Brazilian Market in January, 2013 to substitute the $\mathrm{S} 50$ one $(50 \mathrm{mg} / \mathrm{kg}$ of sulfur), necessary for the new engines with technologies CONAMA P7 and PROCONVE L6 (SUV - sport utilities vehicles and pickups).

In this work, the S10 diesel fuel performance, in terms of emissions, stability and detergency was evaluated. The influence of FAME blending and additives was also studied. Engine tests Peugeot XUD9 and Peugeot DW10 were used as tools for assessing the tendency to form deposits in fuel injectors. The test results confirmed the adequate performance of these low sulfur diesel formulations.
\end{abstract}

\section{INTRODUÇÃO}

Em função da malha de transporte de carga e passageiros ser fortemente baseada no modal rodoviário, o óleo diesel possui uma elevada demanda e importância estratégica no Brasil. A Petrobras trabalha continuamente na maximização do volume de óleo diesel em relação ao petróleo processado, buscando sempre a melhor qualidade do produto para garantir melhor desempenho. A implantação do PROCONVE - Programa Nacional de Controle de Emissões Veiculares por Veículos Automotores em 1986 [1] estabeleceu uma redução gradativa, e expressiva, dos níveis permitidos das emissões veiculares de poluentes que impulsionou o desenvolvimento tecnológico dos motores e das especificações de combustíveis, principalmente do óleo diesel e da gasolina.

Para os veículos do ciclo diesel, a atenção prioritária recaiu sobre as emissões gasosas de óxidos de nitrogênio, denominados $\mathrm{NOx}$ (em função das formações de $\mathrm{NO}$ e $\mathrm{NO}_{2}$ ) e de material particulado (MP). Os óxidos de nitrogênio, por serem irritantes pulmonares, além de serem precursores de chuvas ácidas e de ozônio. O material particulado, por conter partículas 
prontamente respiráveis, podendo ocasionar problemas respiratórios, e por ser vetor de outros poluentes (metais pesados, compostos orgânicos, etc.). O MP consiste em núcleos carbônicos (fuligem) com uma ampla faixa de compostos orgânicos e inorgânicos adsorvidos. Tais compostos são constituídos basicamente de hidrocarbonetos pesados derivados do óleo diesel e do óleo lubrificante, sulfatos derivados do enxofre do combustível, água e metais. Dentre os hidrocarbonetos destacam-se os Hidrocarbonetos Aromáticos Policíclicos (HAP's), cuja identificação tem sido necessária para fornecer informações sobre a magnitude do impacto ambiental dos particulados do óleo diesel. Também foram legisladas as emissões de monóxido de carbono ( $\mathrm{CO}$ ), oriundo da combustão incompleta, e de hidrocarbonetos não queimados (HC) [2].

Com a introdução das diversas fases do CONAMA houve uma redução gradativa do teor de enxofre do óleo diesel no país, atingindo, em janeiro de 2013, $10 \mathrm{mg} / \mathrm{kg}$ de enxofre para a frota de motores CONAMA P7 e L6 [3,4], coexistindo com o óleo diesel de $500 \mathrm{mg} / \mathrm{kg}$ (S500) de enxofre e com o de $1800 \mathrm{mg} / \mathrm{kg}$ (S1800). Cabe ressaltar que a comercialização do S1800 para uso automotivo foi descontinuada a partir de janeiro de 2014. O limite de 10 $\mathrm{mg} / \mathrm{kg}$ de enxofre do óleo diesel nacional é o mesmo estabelecido pela especificação européia EN 590 [5] para o óleo diesel europeu da fase Euro V. A diferença marcante na tecnologia dos motores, desta fase, em relação à fase CONAMA P5, foi a introdução dos sistemas de pós-tratamento dos gases de escapamento (SCR - Selective Catalytic Reduction: catalisador para redução de NOx com injeção de uréia, catalisadores de oxidação, etc.) ou o uso de sistemas de recirculação dos gases de escapamento (EGR - Exhaust Gas Recirculation) [6], como solução tecnológica, para viabilizar o atendimento aos novos limites de emissões.

No sistema de redução catalítica seletiva (SCR) ocorre a conversão dos óxidos de nitrogênio $\left(\mathrm{NO}_{\mathrm{x}}\right)$, em nitrogênio puro $\left(\mathrm{N}_{2}\right)$ e vapor de água, que não causam danos ambientais quando expelidos na atmosfera, mas necessitam de uma solução aquosa de uréia (ARLA 32 - agente redutor líquido automotivo) [7].

No sistema EGR não é usada a solução aquosa ARLA 32, porém é necessária a instalação de uma válvula de controle de recirculação dos gases de escapamento e de um sistema adicional de resfriamento dos gases de escape. Esse sistema reduz a temperatura dos gases de combustão, de forma a reduzir a emissão de $\mathrm{NO}_{\mathrm{x}}$ que está associada diretamente a elevadas temperaturas e à disponibilidade de oxigênio e nitrogênio [8].

A composição química dos combustíveis é fator determinante que influencia no seu desempenho. O óleo diesel é uma mistura complexa de hidrocarbonetos parafínicos; naftênicos; olefínicos e aromáticos. Essas quatro classes de hidrocarbonetos apresentam diferentes propriedades físico-químicas. A proporção de cada uma delas é um dos fatores que pode tornar um combustível tão diferente do outro, apesar do atendimento a uma mesma especificação. É necessário um balanceamento entre os tipos de hidrocarbonetos, heterocompostos (oxigenados, sulfurados, nitrogenados) e contaminantes metálicos, para obter um desempenho adequado do produto no campo [9].

No que tange à qualidade requerida para o óleo diesel, o hidrotratamento consiste na principal rota para produção de combustíveis com baixo enxofre (S10). As unidades de hidrotratamento empregadas são de alta severidade e imprimem mudanças nas propriedades do óleo diesel que podem promover reflexos positivos e negativos no seu desempenho, dependendo fortemente da severidade deste processo; do tipo de petróleo processado e do tipo de carga utilizada. Tais 
mudanças, pelo lado da diminuição de poluentes atmosféricos das descargas dos veículos Diesel, são desejáveis, mas pelo lado da corrosividade, lubricidade, condutividade, etc., se não devidamente contornadas podem resultar em problemas de redução do tempo de vida útil de componentes do sistema de injeção de combustíveis, entre outros [10,11].

A obrigatoriedade da adição de $5 \%$ v/v de biodiesel ao óleo diesel, também consiste em mais um fator de mudança da composição do combustível que pode impactar no seu desempenho [9].

A estabilidade do biodiesel é um fator relevante, pois a estabilidade ruim pode conduzir à formação de ácidos e de polímeros. Os ácidos podem atacar diversos componentes, enquanto que os polímeros podem levar à obstrução de filtros, à formação de sedimentos que se aderem às partes móveis, impedindo seu pleno funcionamento e reduzindo drasticamente o tempo de vida útil do sistema de injeção. Isto pode afetar também equipamentos operados sazonalmente como colheitadeiras ou geradores de emergência e veículos exportados para outros países. Por esta razão, os fabricantes de sistema de injeção recomendam internacionalmente o uso do óleo diesel sem biodiesel para os casos de "primeiro enchimento" ou de uso não contínuo, porém no Brasil esse uso não é autorizado [12].

Adicionalmente, os novos sistemas de injeção de combustível são suscetíveis à formação de uma variedade de depósitos, que podem ocorrer tanto nos orifícios dos bicos de pulverização quanto no interior do corpo dos injetores. A formação desses depósitos internos tem sido objeto de vários estudos, sendo o binômio, tecnologia do motor versus qualidade do combustível, de considerável relevância para mapeamento dos diferentes mecanismos responsáveis pela formação destes depósitos. O desempenho do motor pode ser significativamente alterado pela formação desses depósitos promovendo, além de aumento do consumo de combustível, perda de potência, aumento da emissão de poluentes, etc. A seleção da tecnologia de aditivo de combustível também tem sido estudada como alternativa para manutenção do tempo de vida desses sistemas quer seja, pelo controle da formação desses depósitos (aditivos antioxidantes) ou pela manutenção da limpeza desses sistemas (aditivos detergente / dispersante) [13-15].

Apesar da entrada das tecnologias CONAMA P7 (motores pesados) e L6 (utilitários esportivos e picapes) em janeiro de 2012, ainda não existem muitos trabalhos publicados sobre o uso de combustíveis nacionais e seus impactos no desempenho dos motores com essa nova tecnologia. Esse estudo é relevante no sentido de explicitar o efeito dessas mudanças na qualidade do óleo diesel, no que tange ao desempenho e adequação das novas especificações. São discutidos aspectos relativos ao desempenho em termos de emissão de poluentes, estabilidade, detergência, entre outros atributos, do óleo diesel S10 (tipo A) e de sua mistura com $5 \%$ v/v e $10 \%$ v/v de biodiesel metílico de soja (tipo B). Foi avaliado também o efeito da adição de um pacote de aditivos multifuncional, nas formulações com biodiesel.

\section{DESENVOLVIMENTO DO TRABALHO}

\subsection{Combustíveis da matriz de estudo:}

Uma amostra de óleo diesel comercial S10 e suas respectivas misturas com 5\% v/v e $10 \%$ v/v de biodiesel metílico de soja, sem e com a adição de pacote de aditivos multifuncional, foram submetidas a ensaios de caracterização e de desempenho. Os 
resultados obtidos permitiram, assim, a verificação não só da qualidade de tais combustíveis, como também do efeito da adição de biodiesel e da atuação do pacote de aditivos. Na Tabela 1 está relacionada à identificação de cada amostra.

Tabela 1. Definição dos combustíveis da matriz de estudo

\begin{tabular}{l|c}
\hline \multicolumn{1}{c|}{ Código } & Descrição \\
\hline S10 & óleo diesel S10 comercial, tipo A \\
\hline B5_S10 & $\begin{array}{c}\text { óleo diesel S10, tipo B, com 5\% v/v de biodiesel metílico de soja } \\
\text { (B5) }\end{array}$ \\
\hline B5_S10_adt & B5 aditivado com pacote de aditivos multifuncional \\
\hline B10_S10 & $\begin{array}{c}\text { óleo diesel S10, tipo B, com 10\% v/v de biodiesel metílico de soja } \\
\text { (B10) }\end{array}$ \\
\hline B10_S10_adt & B10 aditivado com pacote de aditivos multifuncional \\
\hline
\end{tabular}

1.2. Ensaios utilizados na caracterização físico-química dos combustíveis:

Na Tabela 2 estão apresentados os ensaios empregados na caracterização físicoquímica dos combustíveis.

Tabela 2 - Normas para caracterização físico-química dos combustíveis

\begin{tabular}{l|c}
\hline \multicolumn{1}{c|}{ Propriedade } & Método ASTM/EN \\
\hline Viscosidade cinemática a $40^{\circ} \mathrm{C}$ & D445 \\
Enxofre & D5453 \\
Massa específica a $20^{\circ} \mathrm{C}$ & D4052 \\
Poliaromáticos & D5186 \\
Número de cetano & D4737 \\
Corrosividade ao aço & D665-B \\
Lubricidade & EN12156 \\
\hline
\end{tabular}

1.3. Ensaios utilizados na avaliação do desempenho dos combustíveis:

Na Tabela 3 estão apresentados os ensaios empregados na avaliação do desempenho desses combustíveis, em termos de emissões veiculares, estabilidade e detergência.

Tabela 3 - Normas de avaliação do desempenho dos combustíveis

\begin{tabular}{|c|c|c|}
\hline \multicolumn{2}{|c|}{$\begin{array}{r}\text { Propriedade } \\
\end{array}$} & Método \\
\hline \multicolumn{2}{|c|}{ - EMISSÕES VEICULARES } & NBR 6601 \\
\hline \multirow[t]{2}{*}{ Não legisladas } & $\left(\mathrm{CO}_{2} \mathrm{e} \mathrm{THC}\right)$ & NBR 6601 \\
\hline & (aldeídos) & Base NBR 12026 - HPLC \\
\hline \multicolumn{2}{|c|}{ - ESTABILIDADE } & \\
\hline \multicolumn{2}{|c|}{ Bioestabilidade a $110^{\circ} \mathrm{C}$} & Rancimat modificado (EN15751) \\
\hline \multicolumn{2}{|c|}{ Estabilidade térmica a $150^{\circ} \mathrm{C}$} & ASTM D6468 \\
\hline \multicolumn{2}{|c|}{ Estabilidade à estocagem a $90^{\circ} \mathrm{C}$} & ASTM D5304 \\
\hline \multicolumn{2}{|c|}{ - DETERGÊNCIA } & \\
\hline \multicolumn{2}{|c|}{ Restrição de fluxo } & Peugeot XUD9 \\
\hline \multicolumn{2}{|c|}{ Perda de potência } & Peugeot DW10 \\
\hline
\end{tabular}

\subsubsection{Emissões:}


Foi realizada a avaliação de emissões de poluentes veiculares legislados: NMHC - Hidrocarbonetos do tipo não-metano; CO - Monóxido de carbono; NOx Óxidos de nitrogênio; MP - Material particulado, além da medição de poluentes não legislados: $\mathrm{CO}_{2}-$ Dióxido de carbono; THC - Hidrocarbonetos não queimados totais $\left(\mathrm{NMHC}+\mathrm{CH}_{4}\right.$ ) e aldeídos, dos combustíveis $\mathrm{BX}$ aditivados e do B5 sem aditivo. Foi utilizado um veículo com tecnologia L6 do CONAMA (picape com 4 cilindros, 16 válvulas, 2.8 litros, turbo, common rail), na condição original de fábrica, ou seja, sem qualquer modificação em seus sistemas de alimentação, injeção, motor ou pneu.

Os testes de emissões de poluentes legislados consistiram em, pelo menos, três ensaios de emissões consecutivos, de ciclo urbano em dinamômetro de chassi, operado por um único condutor, conforme as normas:

- NBR 6601 - Veículos rodoviários automotores leves - Determinação de hidrocarbonetos, monóxido de carbono, óxidos de nitrogênio, dióxido de carbono e material particulado no gás de escapamento.

- NBR 7024 - Veículos rodoviários automotores leves - Medição de consumo de combustível.

A emissão de aldeídos não é legislada para veículos diesel, porém em 2010, o Centro de Pesquisas Leopoldo Américo Miguez de Mello - CENPES participou de trabalhos da Comissão Técnica de aldeídos da AEA, criada em 2009, com o objetivo de subsidiar o IBAMA na elaboração de uma metodologia para a medição de aldeídos totais em motores e veículos do ciclo Diesel. Foram então implantadas metodologias, pioneiras no país, utilizando cromatografia líquida (High-Pressure Liquid Chromatography - HPLC) e FTIR (Fourier Transform Infra Red Analyzer) [16]. Nesse trabalho, os aldeídos foram medidos por cromatografia líquida.

\subsubsection{Estabilidade:}

A estabilidade à oxidação do óleo diesel pode ser avaliada por métodos de envelhecimento acelerado, onde o combustível é submetido a condições que propiciam a degradação de cor e a formação de insolúveis. O tempo, a temperatura e a presença de atmosfera de $\mathrm{O}_{2}$ são variáveis que tendem a aumentar a taxa de oxidação do óleo diesel.

Nesse trabalho a estabilidade à estocagem de todos os combustíveis estudados foi avaliada a partir do método ASTM D5304. Neste método, após o envelhecimento do combustível $\left(16 \mathrm{~h} @ 90^{\circ} \mathrm{C}, 800 \mathrm{kPa} \mathrm{O}_{2}\right)$, é avaliada a tendência à formação de insolúveis. O critério tomado como referência, é insolúveis totais, máximo, igual a 2,5 mg/100 ml.

A estabilidade térmica do óleo diesel, definida como a resistência a mudanças, quando este combustível é submetido a condições de uso em altas temperaturas, também foi avaliada. A deposição de material sólido (coqueamento) nos orifícios de injeção prejudica a atomização e, consequentemente, o desempenho 
do motor. O nível de depósitos depende da qualidade do combustível, ou seja, da sua composição química. Nesse trabalho foi empregado, para estimativa da estabilidade térmica de todos combustíveis estudados, o método ASTM D6468. Neste método, o combustível é submetido à alta temperatura de envelhecimento e à exposição limitada ao ar, simulando o stress térmico que pode ocorrer nos motores durante a recirculação do produto nos sistemas de alimentação de combustível. Neste ensaio, duas alíquotas de $50 \mathrm{ml}$ de amostra são envelhecidas por 90 minutos a $150^{\circ} \mathrm{C}$ em tubos abertos para a atmosfera. Após resfriamento, as alíquotas são filtradas em papéis de filtro Whatman $\mathrm{n}^{\circ} 1$, de $11 \mu \mathrm{m}$ de diâmetro de poro nominal, e a quantidade média de insolúveis é estimada pela determinação da refletância da luz. Os resultados de refletância são fortemente afetados pela coloração dos insolúveis e podem não ser correlacionáveis com a massa do material retido no filtro. Na especificação americana ASTM D975 está estabelecido o valor de refletância, no momento da sua produção, de no mínimo 70\%, após 90 minutos de envelhecimento, para um desempenho satisfatório do óleo diesel.

A estabilidade das misturas BX também foi avaliada pelo método Rancimat modificado (EN 15751 - Automotive fuels - Fatty acid methyl ester (FAME) fuel and blends with diesel fuel - Determination of oxidation stability by accelerated oxidation method). Neste procedimento uma quantidade igual a 7,5 g de combustível é envelhecida a $110^{\circ} \mathrm{C}$ sob fluxo constante de ar $(10 \mathrm{l} / \mathrm{h})$. Os gases efluentes são coletados em água destilada cuja condutividade é constantemente monitorada. A etapa de propagação da reação de oxidação é facilmente observada pelo aumento súbito da condutividade da solução. O tempo decorrido até este aumento é chamado de período de indução e é expresso em horas. Como referência adotou-se o período de indução mínimo de 20 horas.

\subsubsection{Detergência:}

A deposição de material sólido prejudica a atomização e o bom funcionamento do motor em termos de consumo de combustível, potência e emissões. Esse problema pode ser contornado com o uso de aditivos detergentes que impedem a aglomeração de depósitos nos injetores. Assim, a detergência dos combustíveis $\mathrm{BX}$, sem e com a adição de um pacote de aditivos multifuncional, que inclui um componente detergente/dispersante em sua formulação, também foi avaliada a partir de duas metodologias:

- Peugeot XUD9: Método CEC TGD 2301 do Coordinating European Council - CEC. A restrição percentual do fluxo de ar, que é o parâmetro avaliado, é um indicativo da tendência do combustível à formação de depósitos nos bicos injetores. Quanto maior a restrição percentual do fluxo de ar, maior é a tendência à formação de depósitos do combustível. O critério máximo tomado como referência para a restrição de fluxo a $0,01 \mathrm{~mm}$ de levantamento da agulha do injetor é $85 \%$.

- Peugeot DW10: Método CEC F-098-08 - DW10 Diesel Nozzle Fouling Test. A variável resposta é a perda de pressão relativa ao início do teste, indicativa da tendência ao coqueamento de bicos de sistemas de injeção eletrônica de óleo 
diesel de motores de injeção direta, do tipo common rail. O critério máximo tomado como referência para a perda de potência é de $2 \%$.

\section{RESULTADOS E DISCUSSÃO}

$\mathrm{Na}$ Tabela 4 estão apresentados alguns resultados da caracterização físico-química dos combustíveis da matriz de estudo, onde se verifica que, quanto a estes itens, todos os combustíveis atenderam à resolução ANP $\mathrm{N}^{0} 50$, de 23.12.2013 - DOU 24.12.2013, para óleo diesel automotivo S10, tipos $\mathrm{A}$ e $\mathrm{B}$, à exceção da lubricidade do óleo diesel S10 tipo A. Entretanto, a adição de até mesmo $5 \%$ v/v de biodiesel metílico de soja, é suficiente para correção desta propriedade e também da corrosividade ao aço que acusou para o óleo diesel A, valor superior ao recomendado para o óleo diesel automotivo.

Tabela 4 - Resultados da caracterização físico-química

\begin{tabular}{l|l|c|c|c}
\hline \multicolumn{1}{c|}{ Propriedade } & Especificação & S10 & B5_S10 & B10_S10 \\
\hline Viscosidade cinemática a $40^{\circ} \mathrm{C}, \mathrm{mm}^{2} / \mathrm{s}$ & $2,0-4,5$ & 4,386 & 4,363 & 4,323 \\
Enxofre, $\mathrm{mg} / \mathrm{kg}$ & 10,0 máx. & 8,4 & 8,4 & 7,6 \\
Massa específica a $20^{\circ} \mathrm{C}, \mathrm{kg} / \mathrm{m}^{3}$ & $815-850(\mathrm{~A})$ & 848,2 & 849,9 & $851,5\left(^{1}\right)$ \\
& $815-853(\mathrm{~B})$ & & & \\
HC's poliaromáticos $(\mathrm{di}+), \% \mathrm{~m} / \mathrm{m}$ & 11 máx. & 1,1 & - & - \\
Número de cetano & 48 mín. & 52,1 & 51,8 & 52,0 \\
Corrosividade ao aço & B++ & $\boldsymbol{C}$ & $\mathrm{A}$ & $\mathrm{A}$ \\
Lubricidade a $60^{\circ} \mathrm{C}, \mu \mathrm{m}$ & 460 & $\mathbf{5 1 0}$ & 195 & 183 \\
\hline
\end{tabular}

$\left({ }^{1}\right)$ Resolução ANP $\mathrm{N}^{0}$ 2, de 12.01.2011 - DOU 13.1.2011 para misturas B6 a B20: massa específica a $20^{\circ} \mathrm{C}-826$ a $860 \mathrm{~m}^{3} / \mathrm{kg}$.

2.1. Emissões [17]:

- Material Particulado (MP): Na Figura 1 estão apresentados os resultados relativos à emissão de MP. Nesse caso, as médias das emissões apresentam-se inferiores ao limite de emissão de MP de 0,04 g/km da fase L6. Quaisquer dos combustíveis testados não interferem significativamente na emissão de MP.

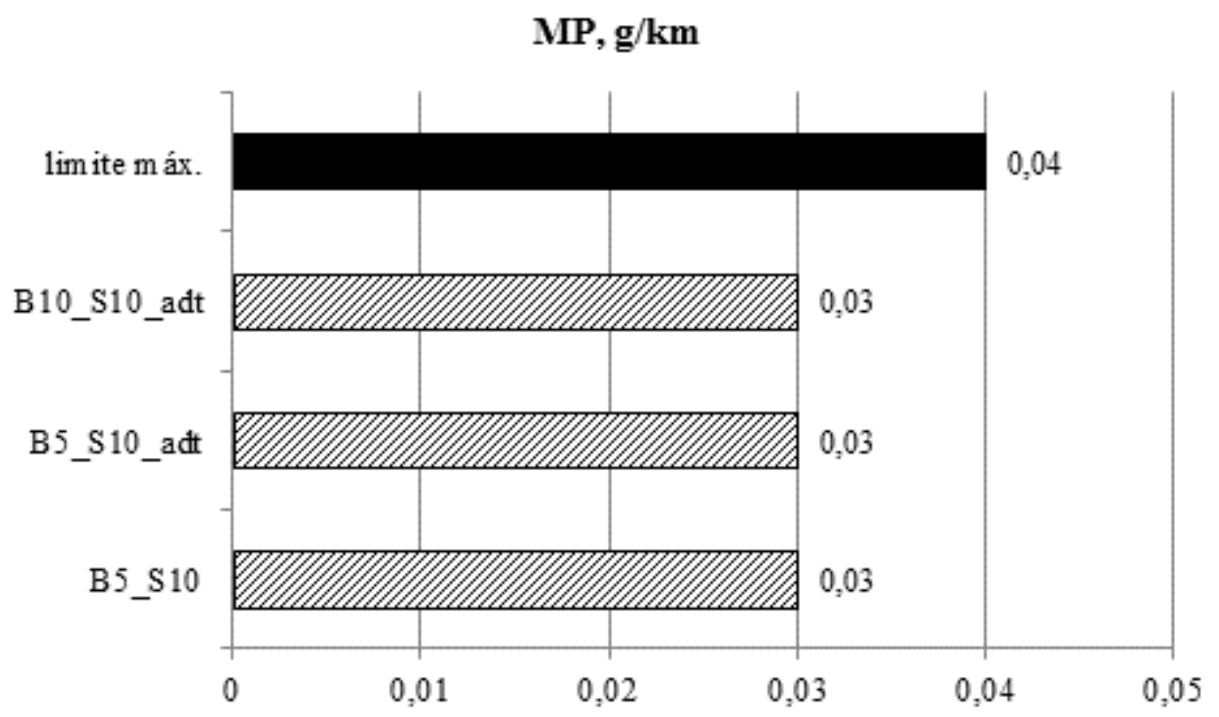

Figura 1 - Emissão de material particulado (MP): Veículo tecnologia L6 CONAMA. 
- Óxidos de Nitrogênio $\left(\mathbf{N O}_{\mathbf{x}}\right)$ : Na Figura 2 estão apresentados os resultados relativos à emissão de $\mathrm{NO}_{\mathrm{x}}$. O limite máximo de $\mathrm{NO}_{\mathrm{x}}$ da fase L6 do CONAMA é de $0,35 \mathrm{~g} / \mathrm{km}$. Pode ser verificado que todos os combustíveis atenderam ao limite, sem considerar a aplicação de fator de deterioração, embora este poluente seja reconhecidamente crítico para os motores Diesel.

NOx, $\mathrm{g} / \mathrm{km}$

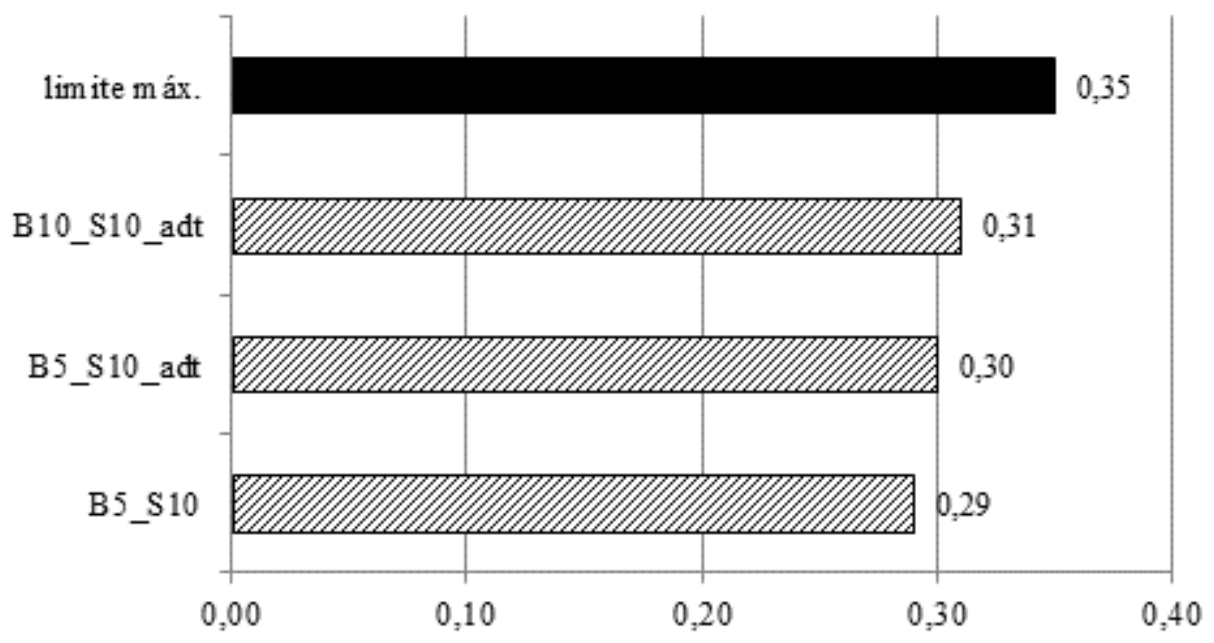

Figura 2 - Emissão de óxidos de nitrogênio (NOx): Veículo tecnologia L6 CONAMA.

- Monóxido de carbono (CO): Na Figura 3 estão apresentados os resultados relativos à emissão de $\mathrm{CO}$. Este poluente é o que mais se correlaciona com as propriedades de volatilidade dos combustíveis [18]. O valor do limite máximo de emissões da fase L6 do CONAMA é 2,00 g/km, ou seja, há uma longa folga deste limite. Historicamente o CO não é um poluente crítico para os motores Diesel, exatamente pelos baixos valores emitidos.

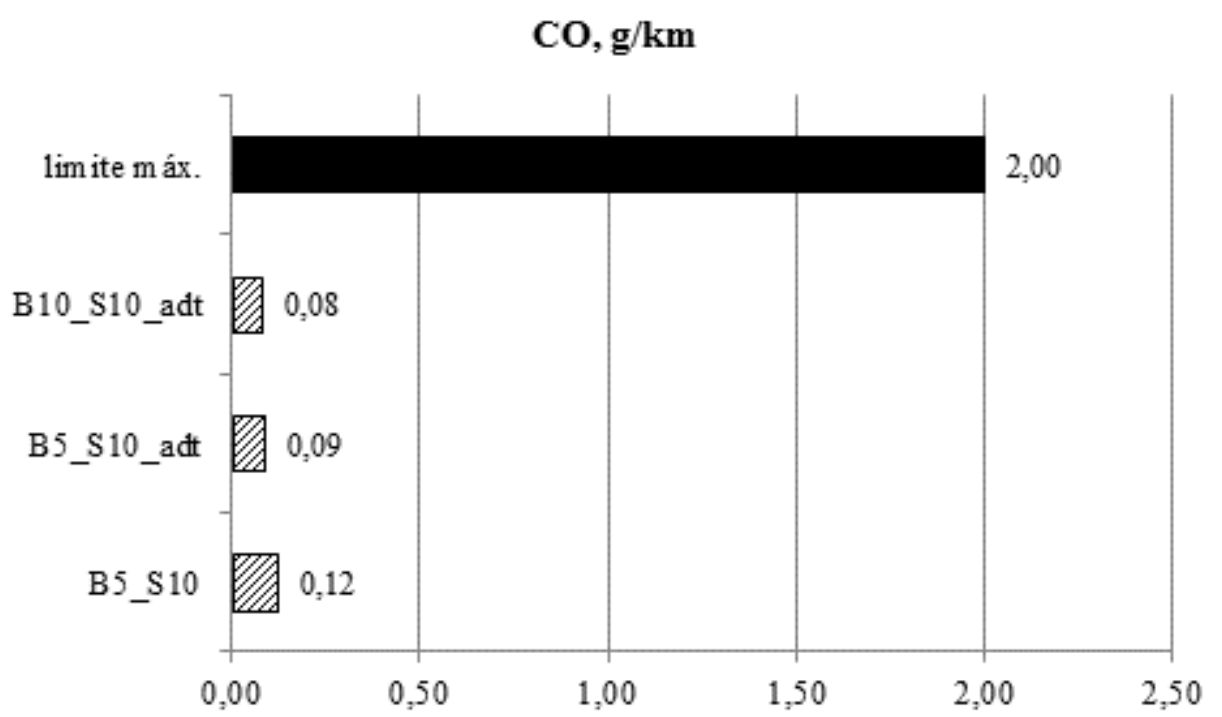

Figura 3 - Emissão de monóxido de carbono (CO): Veículo tecnologia L6 CONAMA. 
- Dióxido de carbono $\left(\mathrm{CO}_{2}\right)$ : Na Figura 4 estão apresentados os resultados relativos à emissão de $\mathrm{CO}_{2}$.

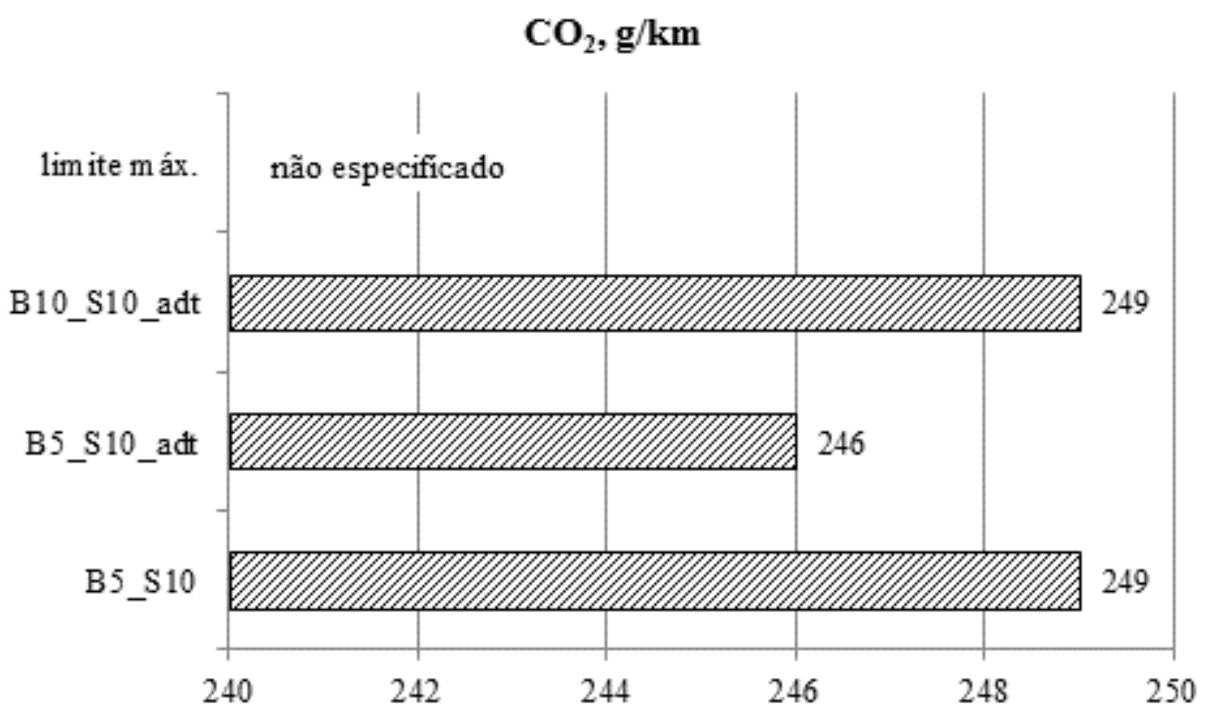

Figura 4 - Emissão de dióxido de carbono $\left(\mathrm{CO}_{2}\right)$ : Veículo tecnologia L6 CONAMA.

- Hidrocarbonetos não queimados totais (THC): Na Figura 5 estão apresentados os resultados relativos à emissão de THC. Todos os patamares absolutos são extremamente baixos, indicando que a influência dos combustíveis na emissão de hidrocarbonetos é desprezível.

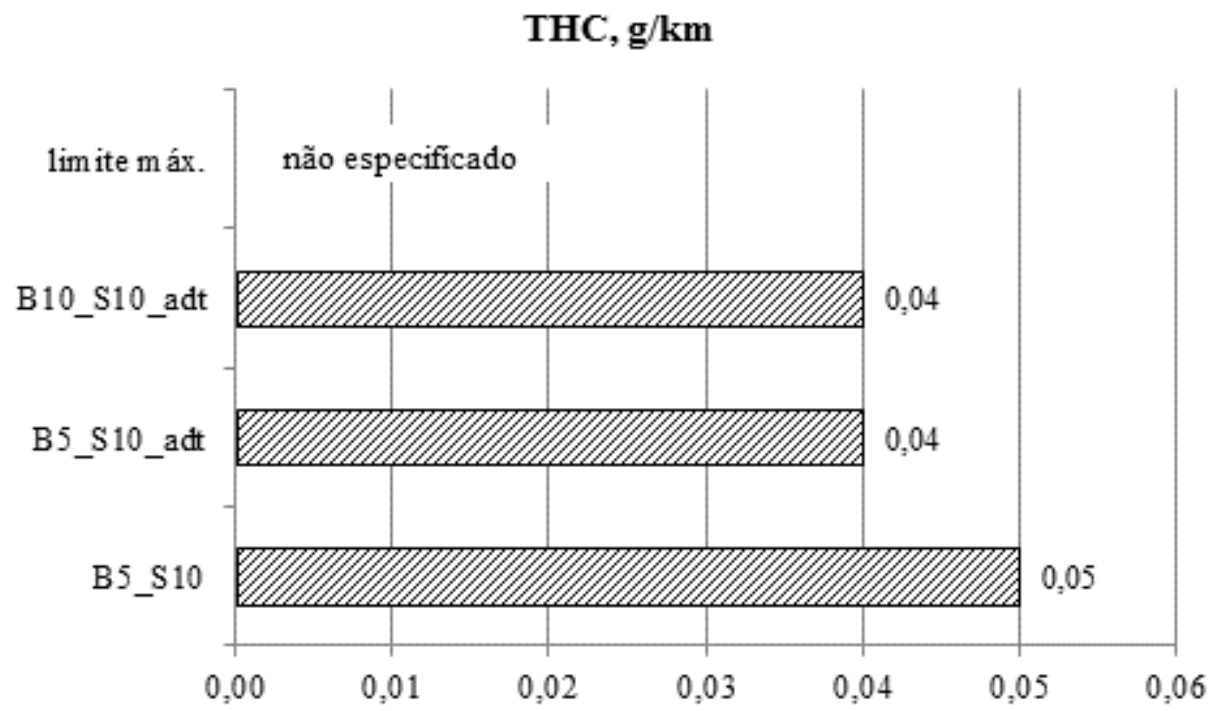

Figura 5 - Emissão de hidrocarbonetos (THC): Veículo tecnologia L6 CONAMA.

- Hidrocarbonetos do tipo não-metano (NMHC): Na Figura 6 estão apresentados os resultados relativos à emissão de $\mathrm{HC}$ tipo não-metano. Todos os patamares absolutos são extremamente baixos, muito inferiores ao limite da fase L6 (0,06 $\mathrm{g} / \mathrm{km}$ ). Assim sendo, em termos práticos, a influência dos combustíveis na emissão de hidrocarbonetos é desprezível. 


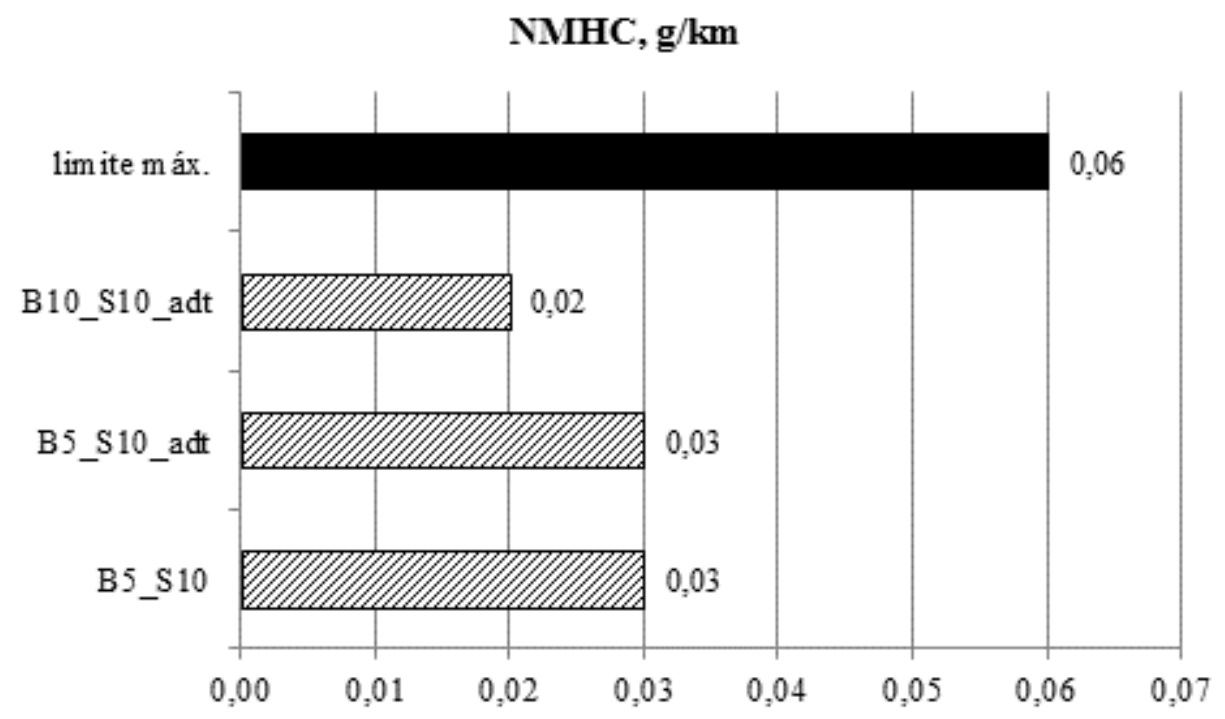

Figura 6 - Emissão de hidrocarbonetos não metano (NMHC): Veículo tecnologia L6 CONAMA.

- Aldeídos: Na Figura 7 estão apresentados os resultados relativos à emissão de aldeídos da formulação B5_S10_adt. Apesar da emissão de aldeídos não ser legislada, o valor de aldeídos totais obtido na formulação B5 aditivada foi bem inferior ao patamar máximo especificado para picapes a gasolina, da fase L6, $30 \mathrm{x}$ $10^{-3} \mathrm{~g} / \mathrm{km}$.

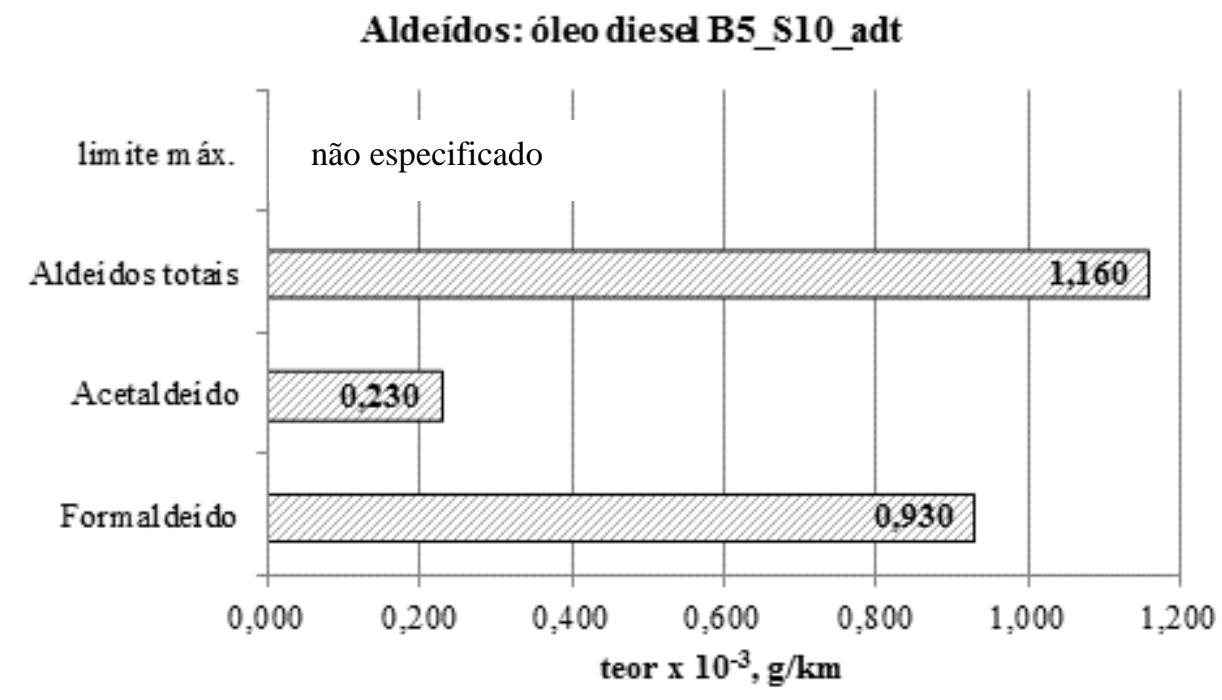

Figura 7 - Emissão de aldeídos: combustível B5_S10_adt em veículo com tecnologia L6 CONAMA.

\subsection{Estabilidade:}

Na Figura 8 estão apresentados os resultados de insolúvel total formados após o envelhecimento das formulações, sob as condições do ensaio ASTM D5304 (16 h @ $90^{\circ} \mathrm{C}, 800 \mathrm{kPa} \mathrm{O}_{2}$ ). Os cinco combustíveis testados apresentaram níveis bem baixos 
de insolúvel total, o que indica excelente estabilidade à estocagem, independente da adição da biodiesel ou da adição do pacote de aditivos.

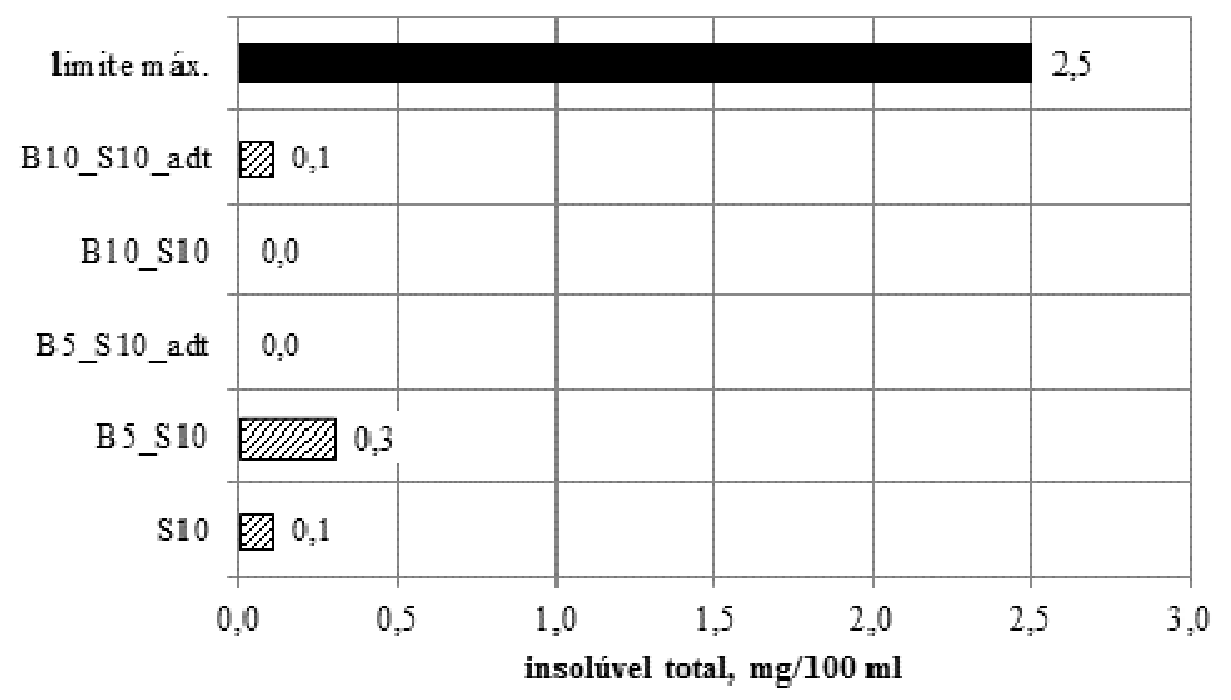

Figura 8 - Estabilidade à estocagem pelo método ASTM D5304 $-90^{\circ} \mathrm{C}$ por $16 \mathrm{~h}$; $800 \mathrm{kPa} \mathrm{O}_{2}$.

Os resultados da estabilidade a alta temperatura dos combustíveis, sem e com biodiesel metílico de soja, sem e com aditivos, a partir do método ASTM D6468, estão apresentados na Figura 9. Todos os combustíveis atenderam com folga ao limite mínimo de refletância estabelecido para o método de estabilidade à alta temperatura.

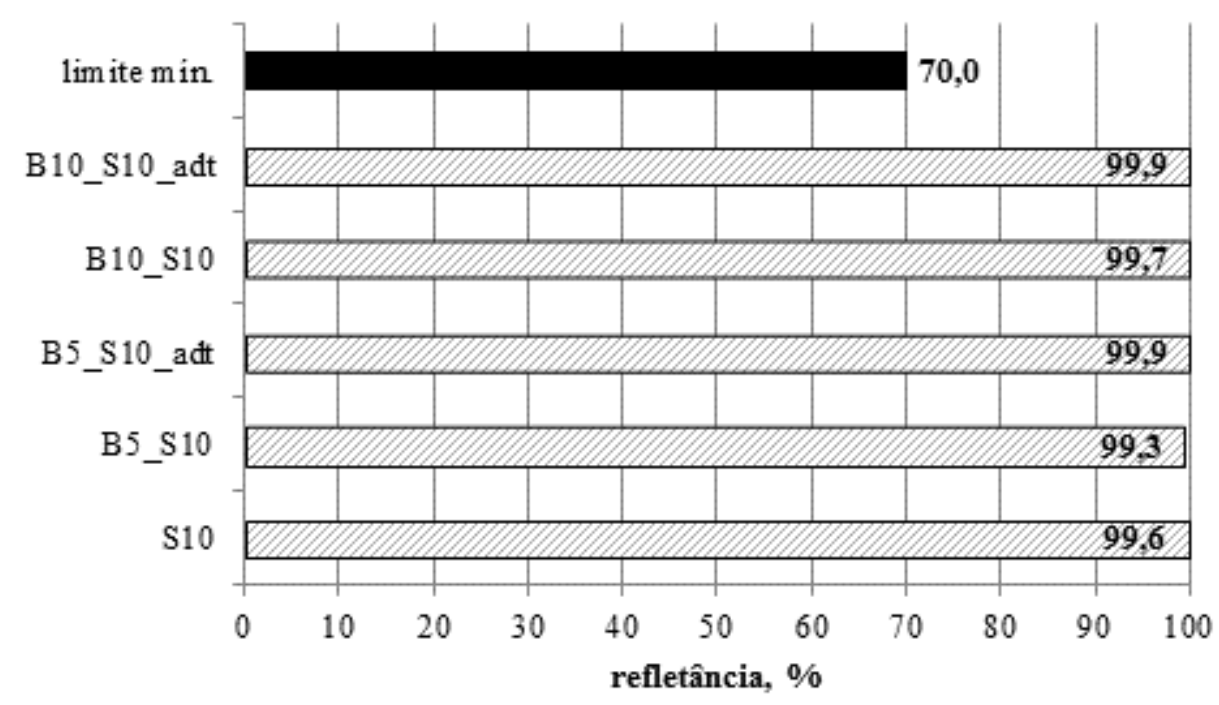

Figura 9 - Estabilidade à alta temperatura pelo método ASTM D6468 $150^{\circ} \mathrm{C}$ por 90 minutos.

A estabilidade das formulações BX pelo método Rancimat Modificado ratificaram o comportamento estável dessas formulações. Na Figura 10 estão apresentados os 
resultados do método EN 15751, onde se verifica que todos os combustíveis apresentaram período de indução adequado, ou seja, superior a 20 horas.

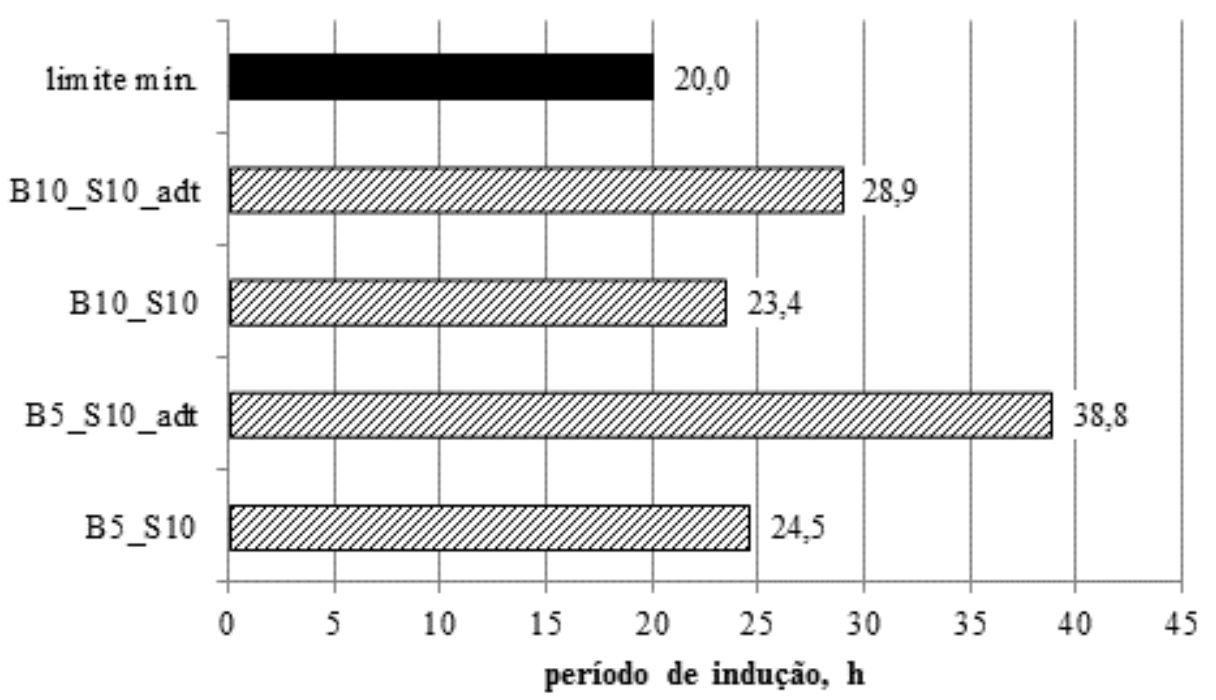

Figura 10 - Bioestabilidade pelo método Rancimat modificado - EN 15751 $\left(\mathrm{T}=110^{\circ} \mathrm{C}\right.$ e vazão de $\left.\operatorname{ar}=10 \mathrm{l} / \mathrm{h}\right)$.

\subsection{Detergência:}

A limpeza dos injetores tornou-se uma prioridade ainda maior com os sistemas de alta pressão de injeção de combustível, em motores de injeção direta. A conformidade de motores modernos com o seu desempenho especificado em termos de potência, consumo de combustível e emissão ao longo do tempo vai depender em grande parte da limpeza de seus injetores.

Os resultados obtidos a partir dos ensaios, Peugeot XUD9, com as formulações BX (Figura 11) e, Peugeot DW10, com as formulações B5 e S10 (Figura 12) permitiram verificar os comportamentos quanto à formação de depósitos desses combustíveis.

- Resultados do Teste Peugeot XUD9: Na Figura 11 estão apresentados os resultados da avaliação da detergência dos óleos diesel tipo B pelo teste Peugeot XUD9. O limite máximo, igual a $85 \%$, recomendado para a restrição de fluxo de ar a $0,1 \mathrm{~mm}$, foi atendido por todos os combustíveis, aditivados ou não. Entretanto, independente do teor de biodiesel, a adição do pacote de aditivos melhorou a detergência em cerca de $40 \%$. 


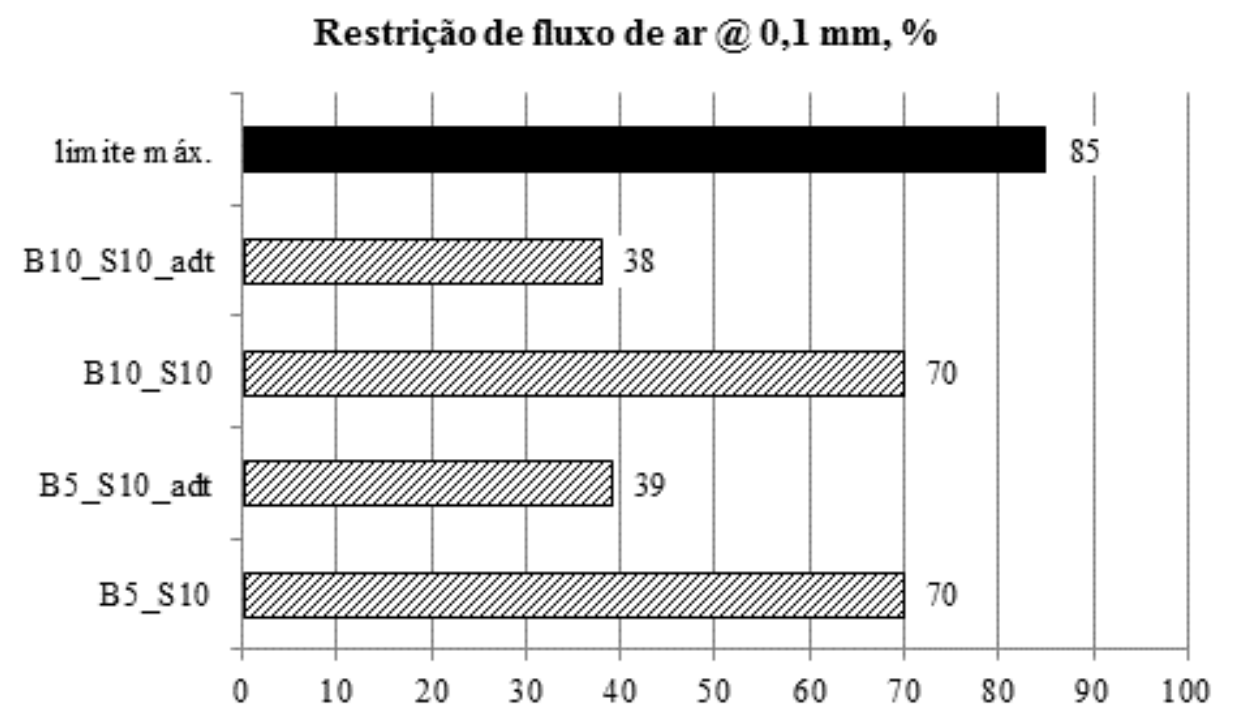

Figura 11 - Detergência: Peugeot XUD9 - Método CEC TGD 2301.

- Resultados do Teste Peugeot DW10: Na Figura 12 estão apresentados os resultados da avaliação da detergência dos óleos diesel pelo teste Peugeot DW10. O limite máximo, igual a $2 \%$, para a perda de potência, foi atendido por todos os combustíveis, com ou sem biodiesel, aditivado ou não.

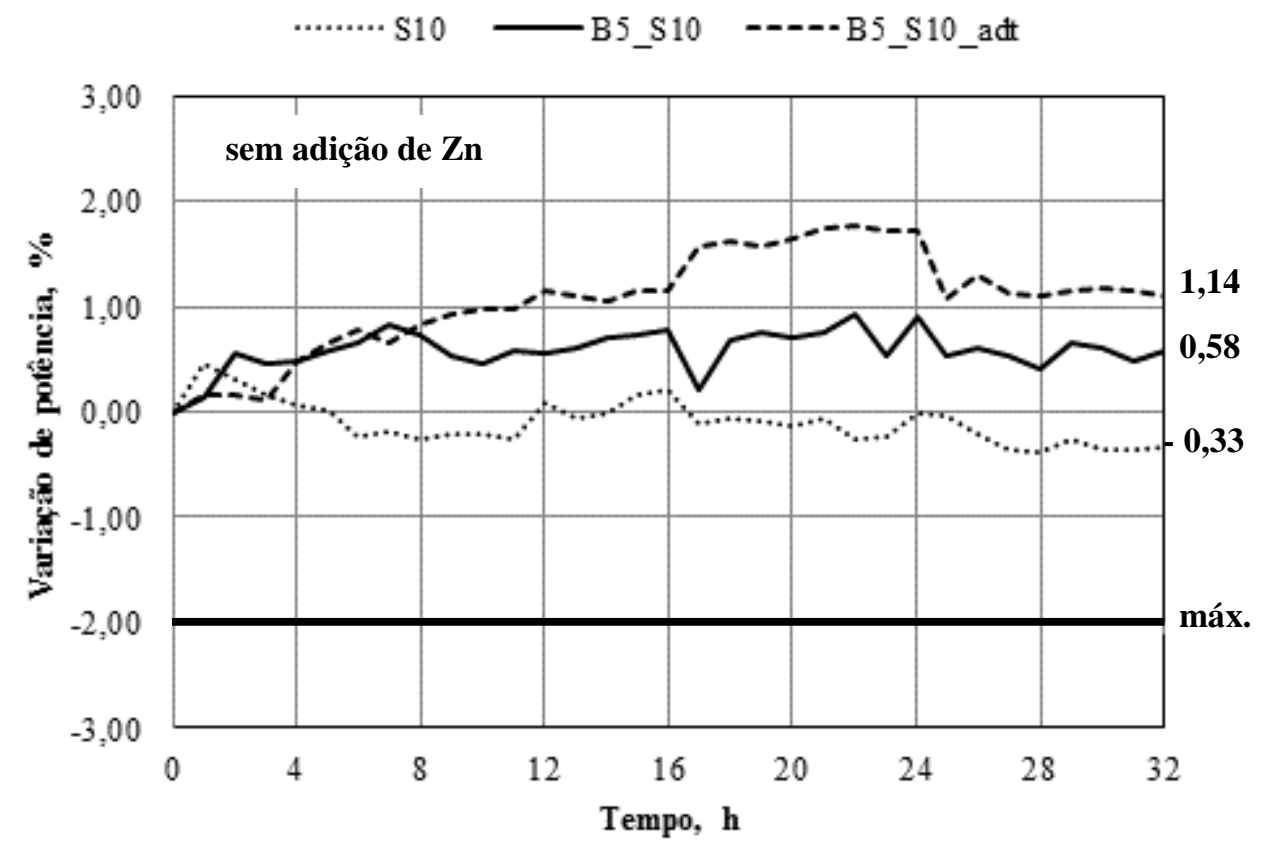

Figura 12 - Resultados do Teste Peugeot DW10 - CEC F-98-08 (Issue 5) - Perda de Potência. 


\section{CONCLUSÕES}

Um programa de testes foi executado para avaliar o desempenho de formulações do óleo diesel S10 quanto às emissões veiculares, estabilidade e detergência. A partir de uma amostra de óleo diesel comercial S10 foram formuladas misturas com 5\% v/v e 10\% v/v de biodiesel metílico de soja, sem e com a adição de pacote de aditivos multifuncional.

Um veículo com tecnologia L6 do CONAMA, que possui sistema de injeção mais moderno da frota de utilitários esportivos do país, foi selecionado para avaliação das emissões legisladas e não legisladas (material particulado - MP; óxidos de nitrogênio - NOx; monóxido de carbono - $\mathrm{CO}$; dióxido de carbono - $\mathrm{CO}_{2}$; hidrocarbonetos não queimados totais - THC; hidrocarbonetos do tipo não etano - NMHC e aldeídos). A estabilidade foi avaliada segundo três abordagens: estabilidade à estocagem, estabilidade térmica e bioestabilidade, decorrente da adição de biodiesel ao óleo diesel tipo A. Para avaliação da detergência foram utilizados os testes Peugeot XUD9 e DW10.

Os resultados obtidos foram satisfatórios com relação à qualidade do óleo diesel ora em uso no mercado nacional, no que se refere ao impacto nas emissões e permitem concluir que dos quatro poluentes legislados avaliados - $\mathrm{CO}, \mathrm{NMHC}, \mathrm{NO}_{\mathrm{x}}$ e $\mathrm{MP}$, nenhum se mostrou crítico com relação ao atendimento aos limites de emissões estabelecidos. O mesmo foi verificado com relação à estabilidade e à detergência.

O resumo qualitativo dos principais resultados obtidos nesse trabalho está apresentado no Quadro 1.

Quadro 1 - Resumo dos principais resultados obtidos

$\begin{array}{lccccc} & \text { S10 } & \text { B5_S10 } & \text { B5_S10_adt } & \text { B10_S10 } & \text { B10_S10_adt } \\ \text { EMISSÃO } & & & & & \\ \text { MP } & \text { ND } & +++ & +++ & \text { ND } & +++ \\ \text { NOx } & \text { ND } & +++ & ++ & \text { ND } & ++ \\ \text { CO } & \text { ND } & +++ & +++ & \text { ND } & +++ \\ \text { NMHC } & \text { ND } & +++ & +++ & \text { ND } & +++ \\ \text { ESTABILIDADE } & & & & & \\ \text { Estocagem } & ++ & +++ & +++ & +++ & +++ \\ \text { Alta temperatura } & +++ & +++ & +++ & +++ & +++ \\ \text { Bioestabilidade } & \text { ND } & ++ & +++ & ++ & +++ \\ \text { DETERGÊNCIA } & & & & & \\ \text { Peugeot XUD9 } & \text { ND } & ++ & +++ & ++ & +++ \\ \text { Peugeot DW10 } & ++ & +++ & +++ & \text { ND } & \text { ND }\end{array}$

Legenda: ND não determinado; +++ muito bom; ++ bom; - - - muito ruim; - - ruim.

Considerando esses resultados, pode-se adicionalmente inferir que:

- O combustível de baixo enxofre (S10) hoje comercializado no mercado nacional, com características semelhantes ao óleo diesel utilizado nesse trabalho, está contribuindo para o atendimento dos limites legislados de emissões pelos motores Diesel da fase L6 do CONAMA (utilitários esportivos e picapes). 
- Alterações composicionais promovidas em função da rota de produção do óleo diesel S10, não impactaram negativamente a estabilidade e a detergência dos combustíveis estudados. Em contrapartida, a lubricidade e a corrosividade ao aço, propriedades que tendem a apresentar problemas com o hidrotratamento severo, são corrigidas com a adição obrigatória de $5 \% \mathrm{v} / \mathrm{v}$ de biodiesel.

- Dentre as características físico-químicas avaliadas destacam-se o alto número de cetano natural e o baixo teor de poliaromáticos, parâmetros que, direta ou indiretamente, contribuem para um pleno funcionamento e para a durabilidade dos motores.

- As formulações, sem e com biodiesel, $5 \%$ v/v e $10 \%$ v/v, apresentaram estabilidade à estocagem e térmica adequadas aos requisitos estabelecidos nesse trabalho. Quanto à bioestabilidade, as formulações B5 e B10, apresentaram períodos de indução em conformidade com o limite mínimo estabelecido na resolução ANP $\mathrm{N}^{\mathrm{0}} 50$, de 23.12.2013 DOU 24.12.2013 tendo, as formulações aditivadas, apresentado valores ainda mais elevados, indicando melhor estabilidade à oxidação. A detergência destes combustíveis, quando avaliada a partir do teste Peugeot XUD9, também indicou bons resultados, sendo que as formulações aditivadas apresentaram desempenho bem superior, independente do teor de biodiesel.

- A detergência das formulações B5, sem e com aditivo, indicou melhor desempenho a partir do teste Peugeot DW10, comparativamente, ao óleo diesel S10, embora esses três combustíveis tenham apresentado resultados inferiores ao limite máximo estabelecido para a perda de potência.

- Os resultados obtidos não indicaram necessidade de alguma ação de adequação da qualidade da formulação B5 atualmente comercializada para uso automotivo.

\section{REFERÊNCIAS}

[1] CONSELHO NACIONAL DO MEIO AMBIENTE, Resolução CONAMA Nº 18, de 06 de maio de 1986, DOU em 17 de junho de 1986.

[2] GOMES, H. O.; MELO, T. C. C.; MASSA, C. V. C.; GIONGO, A. Quality Evaluation of Diesel Fuel S50 Types A and B. SAE 2012-36-0470.

[3] JR. H. J. PROCONVE (Programa de Controle da Poluição do Ar por Veículos Automotores) - As Fases Passadas e Futuras. Seminário sobre Emissões de Veículos Diesel - Comissão de Energia e Meio Ambiente - Anfavea. São Paulo. 27 de outubro de 2009.

[4] CONSELHO NACIONAL DO MEIO AMBIENTE, Resolução CONAMA Nº31, de 14 de outubro de 2009, DOU 15/10/2009.

[5] EN 590:2004/2009 Specifications (Euro 4/5). Automotive Fuels, Diesel. Requirements and Test Methods according to Directive 2003/17/EC e Directive 2009/30/EC.

[6] ROECKER, R.; ZHAN, R. et Alli. Feasibility Investigation of a High-Efficiency NOx Aftertreatment System for Diesel Engines. SAE 2007-01-3983. 
[7] MOONEY, J. J. Diesel Engine Emissions Control Requires Low Sulfur Diesel Fuel. SAE 2000-01-1434.

[8] ZELENKA, P. et Alli. Cooled EGR - A Key Technology for Future Efficient HD Diesels. SAE 980190.

[9] GOMES, H. O. Considerações sobre a Estabilidade à Oxidação do Óleo Diesel. XVIII Simpósio Internacional de Engenharia Automotiva - SIMEA 2010 - 22 a 23/09/2010.

[10] GOMES, H. O. et Alli. Influência Tribológica do Óleo diesel sobre Sistemas de Injeção. XII Simpósio Internacional de Engenharia Automotiva, 12, 2003. São Paulo: AEA, 2003.

[11] ROCHA, M. I.; GOMES, H. O. Óleo Diesel com Baixo Teor de Enxofre Considerações quanto à Lubricidade e Condutividade Elétrica. XVII Simpósio Internacional de Engenharia Automotiva - SIMEA 2009 - Setembro de 2009.

[12] Fuel Requirements for Diesel Fuel Injection Systems - Joint Diesel Fuel Injection Equipment - FIE Manufacturers Statement, issued in Sept. 2009.

[13] ARONDEL, M., RODESCHINI, H., LOPES, M., DEQUENNE, B. Fuel Additives for Reduction of Internal Diesel Injectors Deposits (IDID, "lacquering"): A Critical and Priority Route. SAE Technical Paper 2012-01-1687, 2012.

[14] CAPROTTI, R., BHATTI, N., BALFOUR, G., Deposit Control in Modern Diesel Fuel Injection Systems, SAE Int. J. Fuels Lubr. 3(2):901-915, 2010.

[15] BIRGEL, A., LADOMMATOS, N., ALEIFERIS, P., ZÜLCH, S. et al., Deposit Formation in the Holes of Diesel Injector Nozzles: A Critical Review, SAE Technical Paper 2008-01-2383, 2008.

[16] MELO, T. C. C.; ROCHA, J. R. Como Diferentes Teores de Biodiesel no Diesel Afetam as Emissões de Aldeídos em Motores e Veículos - XXI Simpósio Internacional de Engenharia Automotiva - SIMEA 2013 - Agosto de 2013.

[17] Disponível em http://www.ibama.gov.br/areas-tematicas-qa/programa-proconve (Fase L6 para veículos leves comerciais - massa referência para ensaio maior que $1700 \mathrm{~kg}$ - a partir de 01/01/2012).

[18] GOMES, H. O.; MASSA, C.V.C. e SILVA, R. M. C. F. Óleo Diesel com Baixo Enxofre e as Emissões em Motores com Tecnologia CONAMA P5. XIX Simpósio Internacional de Engenharia Automotiva - SIMEA 2011 - Setembro de 2011. 